\title{
A Study on Grievance Management in Improving Employee Performance in a Pvt Enterprise
}

\author{
Dr.S.Gomathi \\ M.Com.,MBA.Ph.d.,Senior Professor, OB\&HR Team, VIT Business School, \\ VIT university, Vellore-632014, Tamilnadu, India. \\ sgomatthi@vit.ac.in, gommatthi@gmail.com
}

\section{Doi:10.5901/mjss.2014.v5n20p20}

\section{Introduction}

Grievances occur in every workplace and handling them properly is important for maintaining a harmonious and productive work environment. Grievance management is all about how well the problems are addressed (and solved). It is very essential in the present world. Now-a-days there are many companies who declare that their human resources are their most important assets and it is no more human resources but Human Capital. Hence these statements are to be verified whether it is true or not. This can be done by measuring how faster the employees problems are addressed and solved. If it is done faster, then it can be concluded by saying that the employee concern is significantly present in the organization.

The grievances of the employees are related to the contract, work rule or regulation, policy or procedure, health and safety regulation, past practice, changing the cultural norms unilaterally, individual victimization, wage, bonus, etc. Here, the attitude on the part of management in their effort to understand the problems of employees and resolve the issues amicably have better probability to maintain a culture of high performance. Managers must be educated about the importance of the grievance process and their role in maintaining favorable relations with the union. Effective grievance handling is an essential part of cultivating good employee relations and running a fair, successful, and productive workplace. Positive labor relations are two-way street both sides must give a little and try to work together. Relationship building is the key to successful labor relations.

\subsection{Review of litaratue}

"Do We Need To Train Our Managers in Handling Grievances?"by Zulkiflee Daud Mohd Faizal Mohd Isa Wan Shakizah Wan Mohd Nor Zairani Zainol, discusses styles in handling grievances among heads of department at a telecommunication company and the influence of training and experiences in selecting the appropriate grievance handling styles. Finding from this study will help organizations to construct their training framework when especially training in grievance management and leadership. This study has revealed that training result was the significant predictors for the integrating grievance handling style. Training session can enhance heads' of department abilities to convey information regarding company's rules and regulations, terms and conditions of employment and result from precedent cases if the situation and symptom of the present grievance was similar with previous cases. "Grievance expression between co-workers: reliability and validity of a measurement scale" cheryl denise king 's study reports the development of the Grievance Expression Scale (GES), a self-report measurement instrument of how organizational members express objections or complaints that they have about one another's behavior. The GES instrument represents a attempt to better categorize and quantify the behavior of organizational members. Most importantly, the GES stimulates new questions for the stud of conflict communication behavior in organizations and a means for answering those questions. The article titled "save yourself from grief Day, Clive" in Motor Transport; Sep 7, 2006; ABI/INFORM Complete, explains how to avoid greater issues in the organizations. If an employee has a grievance, maybe over money or conditions, then the employer will have to follow strict procedures if he is to avoid potentially expensive compensation claims. The paper looks into grievance and suggests the employers to be updated on the statutory regulation and follow them properly for any kind of grievance.A study done on Non-union grievance systems: System characteristics and fairness perceptions published in Academy of Managemnt journal investigates the fairness perceptions of non-union grievance systems utilizing a policy capturing design. Employees will feel satisfied only $f$ their problems are addressed 
and solved on time. The employees are not expecting a specific systematized procedure to solve their problems but they only require a fir discussion and a result that would solve the problems and let him work peacefully. Grievance resolution: Perceived goal interdependence and interaction patterns by Tjosvold, Dean;Morishima, Motohiro in Relations Industrielles; Summer 1999; identifies behaviors and perceptions of the individuals involved that affect the grievance resolutions. Based on the conflict research the study proposes that cooperative goals promote the direct, open-minded consideration of opposing views which leads to quality solutions efficiently developed. The study identifies grievance handling conditions and skills that lead to effective resolution. Although organizational and environmental conditions are important, representatives may, within these constraints, be able to develop a strong sense of positive interdependence and the skills to interact open-mindedly. These goals and skills should in turn help them to develop integrative solutions that both the management and the union accept.The article on Research on unionized grievance procedures: Management issues and recommendations by Peterson, Richard B;Lewin, David describes Human Resource Management; Winter 2000; critically reviews research on unionized grievance procedure to identify key issues for human resource or labor relations executives and to provide recommendations for dealing with these issues. The review covers psychological, sociological, and economic and industrial relations- based research. Specifically the authors recommend that senior human resource management conceptualize the grievance procedure as a high involvement HR practice, distinguish between the presence and use of grievance procedures, use grievance data to determine whether the grievant or their supervisor suffer management reprisals, assess dominant orientation of the supervisors towards the employees, determine employee perceptions of grievance procedure fairness and monitor the effects of the work force composition and supervisor selection on grievance activity.Workplace grievance procedure by Humphrey, Anna Caterer \& Hotelkeeper, in $A B I$, gives the steps an employee will have to do once he faces the problem. First he should be aware of the problem. Then he should confirm that there is a problem. The problems may be appearing for a moment and disappear suddenly. Or there may not be such problem at all. Then the next stage is to check with legal aspects of the issue. Then take it to the management. Resolution will be stated by the management and then finalize whether the result is accepted. dealing with grievances: the latino experience in pittsburgh, pennsylvania by laura macia-vergara in his article looks into cases of people working in other countries than their motherland. First of all, if migrants remain citizens of their homeland they may be governed by the rights and restrictions of that homeland in regard to a variety of practices such as marriage, divorce, child custody and the inheritance of property. Secondly, incoming populations bring within them different modes of family, social welfare, gender relations and means of organizing claims and rights.

- Transnational migration can be a challenging experience to all migrants, regardless of factors such as legal status, education or type of migration.

- Communities are diverse, and not all programs can be accessed equally by all immigrants.

In the article titled Behavioral Analysis of Grievances: Episodes, Actions and Outcomes by René Bouwen and Paul F. Salipante analyses the behavioral concepts and model of the earlier article by examining the actions taken by grievant, the episodic nature of grievances and grievant' assessments o outcomes. In so doing, it argues that grievance research and practice must be directed towards the dynamics o conflict, cross-cultural differences in grievance behavior and resolution, the impact of third parties, and the effects of grievances on organizational relationships and on individual performance. Synthesizing this article and its predecessor, several implications emerge, all calling for a more behaviora approach on the part of grievance research and practice. Because many grievances are difficult to understand and resolve, they require an analysis of attitudes and behavior. Remedy-seeking responses to wrongful dismissal-Comparing the similarity-attraction and similarity-betrayal paradigms by Cynthia L. Gramm, John F. Schnell and Elizabeth W. Weatherly University of Alabama in Huntsville, Huntsville, Alabama, USA, tells that this study's purpose is to investigate the antecedents of an employee's remedy-seeking behavioral intentions in response to wrongful dismissal. This study is the first to explore relational demographic effects on any type of remedy-seeking response to illegal treatment. Employees who are mistreated may be willing to pursue multiple remedy-seeking options. Organizations need to manage the dismissal process in a manner that encourages a dismissed employee to favor internal remedy-seeking over external remedy-seeking options and that discourages the employee.In this article titled "employee grievances: an application of the leader-member exchange model" by Kelly L. Cleyman,Ford Motor Company \& Steve M. Jex, \& Kevin G. Love Central Michigan University had described in Using the Leader-Member Exchange (LMX) model as a guide, the study examined the relationship between the quality of information exchange between an employee and his or her immediate supervisor and the intention to file grievances. Employees who perceived a high quality information exchange relationship with their supervisors would be less likely to file grievances than employees who perceived a low quality information exchange relationship. Industrial/organizational psychologists have generally neglected the study of employee grievances compared to other variables such as job performance, job satisfaction, absenteeism, and turnover (Muchinsky \& Maassarani, 1980). But the scenario is changing. First, although union membership has declined since the 1950's, many 
employees still belong to unions. Researchers initially postulated that employees who accessed grievance systems were demographically different from employees who did not. Another line of research proposed that differences in work environments produced differences in grievance filing. Another aspect of the work environment that may affect grievance activity is an employee's immediate supervisor. Another aspect of the work environment that may affect grievance activity is an employee's immediate supervisor.Examining employee grievances using the transactional approach to leadership is useful because this approach recognizes that each employee develops a unique relationship with his or her supervisor. It is this unique relationship, rather than general leader behaviors, that is likely to have the most impact on employees. The Author Ochalla, Bryan in his article on Good grievance(Publication info: Credit Union Management 29.6 (Jun 2006), had revealed that the grievances those raised by the employees will also help the management to improve the grievance handling procedures being followed by the organization. The statement stands proved. The grievances that are raised by the employees for sure would help to face the future issues easily as well as it gives multiple insights to the problem and help to deal properly.The Author: Cox, Roxanne; Blum, Albert A; Villa, Jennifer R, in his article "promoting organization fairness in small business: an analysis of grievance procedures" provides a brief theoretical review of the three different conceptual perspectives on procedural justice as they relate to dispute resolution. a grievance procedure that will allow employees not only more process and decision control, but will address the interactional elements of procedural justice is provided as a result of conducting a survey. In Behavioral Analysis of Grievances on Conflict Sources, Complexity and Transformation by Paul F. Salipante and René Bouwen had opined Grievances are usually complex but are typically reformulated and misrepresented to fit acceptably simplistic classifications.

Given what is known about grievance complexity and transformation, researchers should similarly use behaviorally based classifications such as those proposed here. To do so, they must move to interview or survey methodologies. The study implies that interview-based data collection, and that of others such as Kuhn [researcher], shows the value of using a better methodology to investigate the causes of grievances, not just the formally labeled grievance issue, the procedural steps followed, and the most visible outcomes.Effective Grievance Handling Procedures by Hunter, Sonia; Kleiner, Brian H Publication info: Management Research News explains about Some of the most common complaints by employees include unfair treatment by the employer, broken employment agreement, and employer communications and defamation. The most common employers' complaints are absenteeism, insubordination, misconduct, substance abuse, unsatisfactory performance, and safety and health violations. For grievance handling to be effective, the employer has to follow certain guidelines. In disciplining employees, management should mainly use penalties such as warnings, suspensions, and discharge. The study reveals that the employer should follow some set of guidelines. Following the guidelines allows for transparency, and no room for possible action for damages.Employee Grievance Programs: Understanding the Nexus between Workplace Justice, in Organizational Legitimacy and Successful Organizations by the Author: Haraway, William M, III in Publication info: Public Personnel Management 34.4 (Winter 2005), had focused on the inevitable tension between management prerogatives and employee rights in the public workplace. The study concludes that workplace justice and organization success are closely tied to the legitimate to design institutions capable of fulfilling their social responsibilities in self-preserving ways. This will require a better understanding of how formal employee grievance procedures alter cooperative, alternative dispute resolution mechanisms for resolving employees' workplace concerns, complaints, and disputes in public organizations.Grievance management and its links to workplace justice by Lawrence Nurse and Dwayne Devonish Department of Management Studies, University of the West Indies, Bridgetown, Barbados in the Jouranal of Employee Relations,2007, explored the influence of workers' demographic characteristics on their perceptions of procedural justice from grievance management. This study found that with the exception of educational background, demographic characteristics made no significant difference to workers' perceptions of procedural justice afforded by grievance procedures. The study concluded saying that the potential contribution that grievance procedures can make to organizational justice can only be maximized if managers and trade-union leaders pay attention to the effectiveness of the governance structures that they employ for dealing with workplace grievances and to the quality of the outcomes that derive from their usage..In the article titled "Research on unionized grievance procedures: Management issues and recommendations"by Peterson, Richard B; Lewin, David in his Publication info: Human Resource Management 39.4 (Winter 2000): describes about the fact that it is relatively clear that younger, male, more educated, and more skilled employees are most likely to file grievances; considerate or democratic supervision is associated with lower grievance filing rates; and employee complaints to shop stewards are a harbinger of formal grievance filing. The grievances are being reported and required steps are taken by a set of people who find that the grievances are to be properly carried for better performance and satisfaction. The article

Supervisor and manager styles in handling discipline and grievance Part one - comparing styles in handling discipline and grievance by Caroline M. Hook, Derek J. Rollinson, Margaret Foot and Janet Handley University of Huddersfield, Huddersfield, UK 
Personnel Review 25,3, 1990, compares the handling styles used by managers and supervisors in order to examine whether a common style is used in both situations. The study reveals that the supervisors and managers tended to prefer more participative styles when dealing with grievance handling. This links clearly to Wright and Taylor's indications that this would be a suitable approach to the handling of grievance issues. However the exception was when the managers and supervisors appeared to perceive a situation as a direct threat to their authority and here they reverted to a much more autocratic style similar to that often expected in a disciplinary situation.

The authors,Derek Rollinson, Caroline Hook, Margaret Foot and Janet Handley School of Business, University of Huddersfield, Huddersfield, UK in Personnel Review on the title Supervisor and manager styles in handling discipline and grievance narrates the relative importance of some of the factors that most influence the styles adopted.

- Supervisor biographic and position factors

- Issues factors

- Employee factors

- Procedural factors

While some managers and supervisors in the sample had received training in discipline and/or grievance handling, there must be reservations about its effectiveness in terms of promoting sound practice. For example, a proportion was not even aware whether their employing organization had discipline and grievance procedures, let alone the details of their contents. This indicates that there is an obvious need to give serious consideration to the training that supervisors and managers receive in what can often be highly problematic issues. The longer tenured employees are more likely than those with short service to have their cases handled in an exploratory way is cause for some concern. The study concludes by saying that these factors have implications. The article titled,Supervisor and manager approaches to handling discipline and grievance: a follow-up study by Derek J. Rollinson Huddersfield University, Huddersfield, UK examines the relative influence of factors affecting the approach of supervisors or managers to dealing with disciplinary or grievance incidents. For discipline the most influential factors are identified as: the inconvenience of the employee rule transgression and the length of an employee's service, with comparatively minor effects for employee gender, manager gender, prior training and experience in handling issues, and whether an organization is unionized. With grievance the most influential factors are: the challenge to management authority of an issue, length of employee service, employee gender and to a lesser extent the age and gender of the manager, and whether the organization is unionized.

\subsection{Statement of the problem}

The problem to be addressed is to assess the Grievance management and procedures followed by a Pvt. Ltd. to solve the grievances of the employees. There are various factors that motivate the employees to work for an organization and make them retain in the organization for a longer period of time. There are factors that will exhibit whether the employees' grievances are addressed and solved properly or not. The factors considered here include the awareness of the problem, the awareness of the employees whom to report, the availability of the concern person, discussion of the problems, causes and effects, methods to avoid such problems in future, directions and instructions regarding how to deal a problem, awareness programs to avoid them for fresh employees, etc. Though many studies have dealt with Grievance Management and Procedures, this study is a pioneer attempt $n$ Private Group of Enterprises to probe into their Grievance Management. The researcher also evinced interest to study the Grievance Management of the selected firm.

\section{Objective of the Study}

- $\quad$ To know the Grievance Management System prevailing in a Pvt.Enterprise.

- To understand how far the employee's grievances are redressed.

- To understand the various factors that influence employees to retain in the organization and support the management in future.

- To bring out those factors to the management concerning employees so as to improvise the organizational performance.

\subsection{Scope of the study}

The scope of the study is extended to the employees of a Pvt. Ltd., This study is applicable to a set of employees of the same nature. This study has significant importance in the present as well as in future. The topic selected for the study is 
an important key to make the employees satisfied and motivated to work for the organization whereby the employees will also look at their career positively.

\section{Research Methodology}

\subsection{Type of study}

Descriptive method is used for the study. Direct interview is done with many respondents who find it difficult in answering the questions themselves. Translation is done whenever and wherever required.

\subsection{Sample size Table No. 1.6.4}

\begin{tabular}{|l|c|c|c|}
\hline No. of respondents & Total population & Samples & $\%$ of sample to the total population \\
\hline Executive & 65 & 4 & $0.80 \%$ \\
\hline Middle & 80 & 25 & $5.00 \%$ \\
\hline Lower Total & 855 & 471 & $94.20 \%$ \\
\hline & 1000 & 500 & $100 \%$ \\
\hline
\end{tabular}

\subsection{Tools used}

A structured questionnaire is prepared and being circulated which contains set of statements so that the respondent will find it easy to give the level of agreement on the given statements. The questions are structured in such a way that the respondents will be easy to understand the topic and answer properly.

\subsection{Collection of data}

Primary data was collected through interviews with personnel of different cadres of different departments regarding the roles and responsibilities carried out and the functioning of the department. Secondary data was collected from the books, registers and website of the company, interviews and through observations.

\subsection{Limitations of the study}

The Major Limitations of the study are: Cost Limitation: There was a cost limitation. This means that we couldn't offer any gift or monetary incentives for the respondents to answer the questionnaire. This might have resulted in certain prospective respondents choosing not to respond to the questionnaire. This might not have created a motivation among respondents not to take a chance to give opinions.

Time Limitation: There are two types of time limitation faced during the study.

The study was done for a period of eight weeks. Hence the results would reflect the impact of the time constraint. The insights of the employees were observed during the period of study. A more extensive study conducted over a larger time period or during a special period of time like when there were higher numbers of issues, can include insights from employees over a broader time period and can bring in further depth into the research.

\subsection{Statistical techniques used in this study}

SPSS, a software for analysis is used to analyze the collected data and the results are interpreted with care and caution. Charts and tables are prepared for each and every question in the questionnaire so that the collected data is fully utilized. Factor analysis and reliability tests are done.

The data collection is done with the help of a questionnaire with statements regarding the grievance handling procedures that are being followed by the management. Respondents are requested to fill in their opinions and level of agreements with regard to each statement in the questionnaire. The data collected with questionnaire as an instrument is entered in Excel for analysis purpose and tabulated below.

Tabulation 
Table 1: Factor Analysis

\begin{tabular}{|c|c|c|c|c|c|}
\hline No. & Factor name & Statement & Mean & SD & No. of items \\
\hline \multirow{3}{*}{1} & \multirow{3}{*}{$\begin{array}{l}\text { Awareness of the problem and } \\
\text { reporting person }\end{array}$} & I am aware of the problem that happens in my work area & 3.88 & .972 & \multirow{3}{*}{3} \\
\hline & & I know whom to report & 4.14 & .906 & \\
\hline & & The person is available (to whom you should report) & 3.88 & 1.019 & \\
\hline \multirow{2}{*}{2} & \multirow{2}{*}{ Discussion and reporting } & I have discussed with others or Union members & 3.84 & 1.021 & \multirow{2}{*}{2} \\
\hline & & I have reported the problem immediately & 4.02 & 1.007 & \\
\hline \multirow[b]{2}{*}{3} & \multirow[b]{2}{*}{ Management immediate reaction } & Management has accepted the proposal & 3.82 & 1.069 & \multirow[b]{2}{*}{2} \\
\hline & & $\begin{array}{l}\text { Management has inspected / checked in person to the } \\
\text { problem area }\end{array}$ & 3.99 & .941 & \\
\hline \multirow[t]{2}{*}{4} & \multirow[t]{2}{*}{ Steps taken by management } & $\begin{array}{l}\text { Management has communicated to the concern people } \\
\text { involved in the problem }\end{array}$ & 3.86 & 1.073 & \multirow[t]{2}{*}{2} \\
\hline & & Management has identified the root causes of the problem & 4.04 & .987 & \\
\hline \multirow{2}{*}{5} & \multirow{2}{*}{ Solving the issue } & Management has taken steps to solve the problem & 3.93 & 1.067 & \multirow{2}{*}{2} \\
\hline & & The problem is fully solved & 3.86 & 1.010 & \\
\hline \multirow{2}{*}{6} & \multirow{2}{*}{ Involvement and satisfaction } & Am ready to give other solutions & 3.88 & 1.002 & \multirow{2}{*}{2} \\
\hline & & Am satisfied with the solutions arrived & 3.88 & 1.005 & \\
\hline \multirow[t]{2}{*}{7} & \multirow[t]{2}{*}{ Satisfaction and future support } & $\begin{array}{l}\text { Am satisfied with procedure followed by the management to } \\
\text { solve the issue }\end{array}$ & 3.92 & 1.001 & \multirow[t]{2}{*}{2} \\
\hline & & In future I will support the management & 3.95 & 1.076 & \\
\hline \multirow{2}{*}{8} & \multirow{2}{*}{ Encouraging self and others } & I will also report my personal problems (related to the job) & 4.15 & .998 & \multirow{2}{*}{2} \\
\hline & & I will encourage others to report their problems & 3.93 & 1.118 & \\
\hline \multirow{2}{*}{9} & \multirow{2}{*}{ Before and after an sisue } & $\begin{array}{l}\text { Awareness program was conducted in relationship with the } \\
\text { problem }\end{array}$ & 4.05 & .988 & \multirow{2}{*}{2} \\
\hline & & $\begin{array}{l}\text { The management has already given you instructions for such } \\
\text { problems }\end{array}$ & 3.95 & 1.020 & \\
\hline \multirow{3}{*}{10} & \multirow{3}{*}{ Safety measures } & I know what to do first when an accident occurs & 3.92 & 1.047 & \multirow{3}{*}{3} \\
\hline & & I know whom to report the accident immediately & 3.98 & 1.014 & \\
\hline & & Safety precautions and equipments are provided properly & 3.99 & 1.022 & \\
\hline
\end{tabular}

Table 2: Scale Statistics

\begin{tabular}{|c|c|c|c|}
\hline Mean & Variance & Std. Deviation & N of ltems \\
\hline 86.85 & 37.675 & 6.138 & 22 \\
\hline
\end{tabular}

The overall men value is 86.85 , variance is 37.675 and the final set of rotation has 22 statements.

Table 3: Reliability Statistics

\begin{tabular}{|c|c|c|}
\hline Cronbach's Alpha & Cronbach's Alpha Based on Standardized Items & No. of Items \\
\hline .414 & .416 & 22 \\
\hline
\end{tabular}

Cronbach's alpha value is 0.416 for 22 statements. 
Table 4: Rotated Component Matrixa

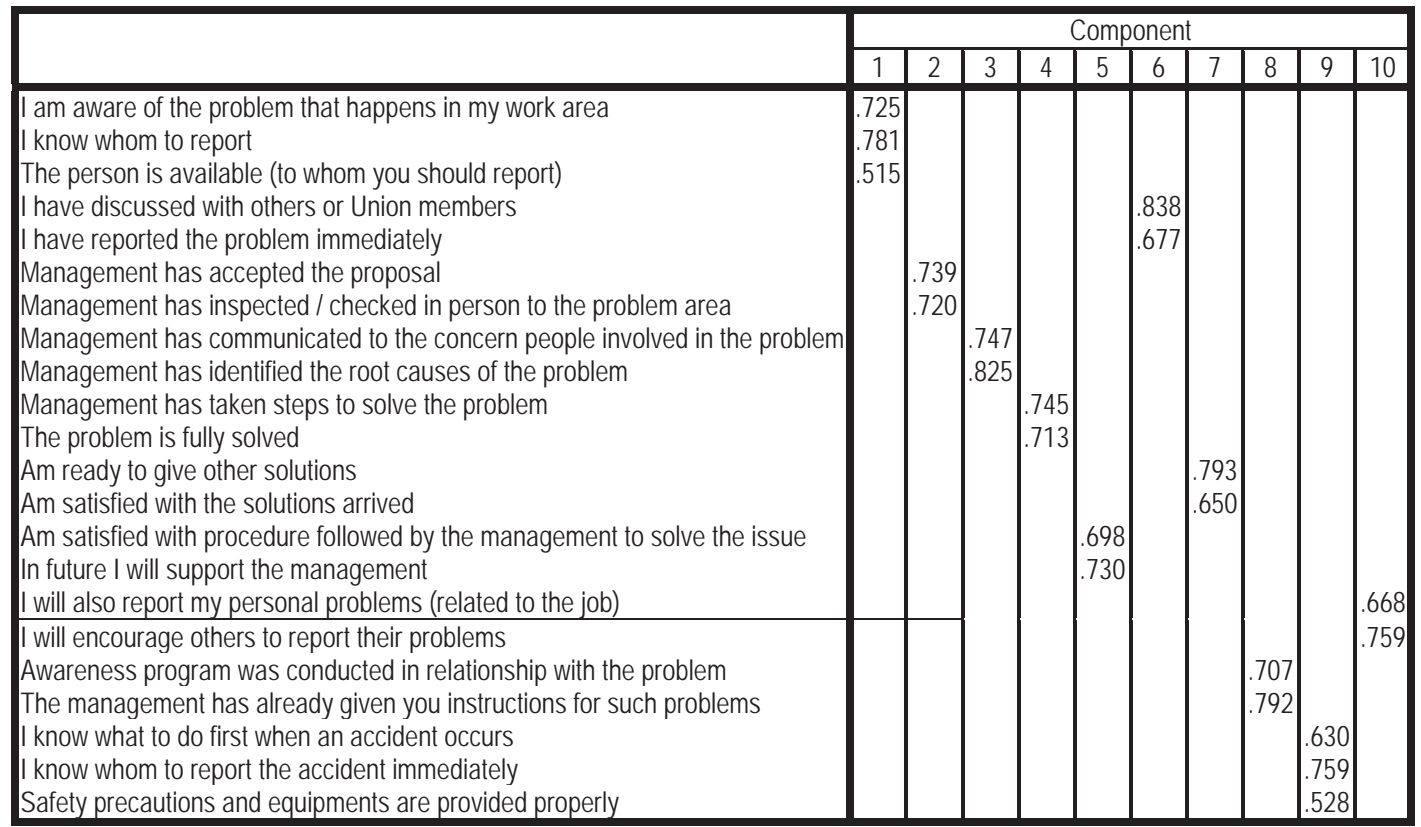

Extraction Method: Principal Component Analysis.

Rotation Method: Varimax with Kaiser Normalization.

\section{Findings}

$86.2 \%$ of the respondents belong to the category of Age -18 to 28 years and $1.0 \%$ of the respondents belong to the category of Age -40 to 50 years.

Among the samples $65 \%$ are from the production department. The least number of respondents belong to the security category for about $0.4 \%$.

$94.2 \%$ of respondents belong to the operator category. Only $0.8 \%$ of the respondents belong to the executive category.

Nearly half of the respondents are working in the company for less than 1 year for about $50.8 \%$. And the meager category of $1.4 \%$ is respondents working in the same company for above 10 years.

$69.2 \%$ of the respondents belong to the category of employees who are earning salary of less than Rs.5000. And $1.4 \%$ of the respondents earn above Rs.10000.

$70.2 \%$ of respondents are aware about the union. And the remaining $29.8 \%$ of the respondents are not aware of the union.

About $12 \%$ of the respondents belong to union. And remaining $88 \%$ of respondents do not belong to union.

There are about $2 \%$ of employees who strongly disagree the statement on the awareness of the problem. There are about $43.2 \%$ of respondents who agree the statement on the awareness.

There are about $7.6 \%$ of employees who disagree the statement that they know whom to report. There are about $41.2 \%$ of employees who strongly agree the statement.

There are about $1 \%$ of employees who strongly disagree the statement on the availability of the person to report the problem. There are about $38.8 \%$ of employees who agree the statement.

There are about $1 \%$ of employees who strongly disagree the statement on discussing the problem with others and Union members. There are about $40.8 \%$ of employees who agree the statement.

There are about $1.6 \%$ of employees who strongly disagree the statement on reporting the problem immediately. There are about $39.6 \%$ of employees who strongly agree the statement.

There are about $1.4 \%$ of employees who strongly disagree the statement on management accepting the proposal to solve the problem. There are about $38.4 \%$ of employees who agree the statement. 
There are about $0.8 \%$ of employees who strongly disagree the statement on the management checking or inspecting the problem area directly. There are about $39 \%$ of employees who agree the statement.

There are about $1 \%$ of employees who strongly disagree the statement on whether the management is understanding the problem or not. There are about $43 \%$ of employees who strongly agree the statement that the management understanding the problem.

There are about $1.2 \%$ of employees who strongly disagree the statement on management communicating the problem with the concern employees. There are about $38.2 \%$ of employees who agree the statement.

There are about $1.4 \%$ of employees who strongly disagree the statement on management identifying the root causes of the problem. There are about $38.8 \%$ of employees who strongly agree the statement.

There are about $1.2 \%$ of employees who strongly disagree the statement on management discussing the root causes of the problem with the concern employees. There are about $39.4 \%$ of employees who agree the statement.

There are about $1.4 \%$ of employees who strongly disagree the statement on management taking steps to solve the problem. There are about $37.4 \%$ of employees who strongly agree the statement.

There are about $0.8 \%$ of employees who strongly disagree the statement on whether the problem is fully solved. There are about $38 \%$ of employees who agree the statement.

There are about $1.2 \%$ of employees who strongly disagree the statement on whether the employees are ready to give some possible solutions. There are about $40.4 \%$ of employees who agree the statement.

There are about $2 \%$ of employees who strongly disagree the statement on the satisfaction of employees with the solutions arrived at. There are about $41.4 \%$ of employees who agree the statement.

There are about $0.8 \%$ of employees who strongly disagree the statement on the procedure followed by the management to solve the problem. There are about $42.4 \%$ of employees who agree the statement.

There are about $1.6 \%$ of employees who strongly disagree the statement in supporting the management in future. There are about $39.4 \%$ of employees who strongly agree the statement.

There are about $1.2 \%$ of employees who strongly disagree the statement on reporting the personal problem (related to the job) to the management. There are about $46.6 \%$ of employees who strongly agree the statement.

There are about $1.8 \%$ of employees who strongly disagree the statement on encouraging others to discuss their problems to the management. There are about $39.4 \%$ of employees who strongly agree the statement.

There are about $1 \%$ of employees who strongly disagree the statement regarding the awareness program being conducted in relation with the problem. There are about $40 \%$ of employees who strongly agree the statement.

There are about $.8 \%$ of employees who strongly disagree the statement on the management giving instructions for such problems. There are about $35.8 \%$ of employees who agree the statement. There are about $35.8 \%$ of employees who strongly agree the statement.

There are about $1.4 \%$ of employees who strongly disagree the statement on the awareness of the first aid procedures. There are about $38.2 \%$ of employees who agree the statement.

There are about .8\% of employees who strongly disagree the statement regarding the knowledge of what to do when an accident occurs. There are about $36.0 \%$ of employees who strongly agree the statement.

There are about $12.4 \%$ of employees who disagree the statement on knowing the person whom to report about the accident. There are about $37.8 \%$ of employees who strongly agree the statement.

There are about $12.8 \%$ of employees who are neutral to the statement on safety precautions and equipments being provided. There are about $38.6 \%$ of employees who strongly agree the statement.

\section{Suggestions}

The company is a typical company that runs by employing people nearby its location. The employees at higher levels are educated and selected via interviews. But the employees in lower cadres are appointed with the contractors as the basis of information. They bring in people for work. Such employees do not have a good education background. Hence the company can follow

- Training on Communication, body language (concerning behavioral aspects).

- Education and training on Employee Morale.

- Awareness program regarding the ESI and PF benefits, various labor laws and employee welfare schemes.

- Discussion on the Vision and Mission statements of the company and the ways to achieve.

- More clarity on roles and responsibilities to be carried out by individuals (Duties and rights).

- Education on Occupational safety. 
- Awareness on importance of education.

- Employees participation, suggestion, ideas need to be encouraged by the supervisor which will surely motivate the employees and will result in higher level of job satisfaction. This cannot be done immediately and it will not be encouraged by all employees suddenly, it will take time to be involved. Still it is very good for the employees as well as the company.

- A system of suggestion box can be implemented which will facilitate the employees to give their suggestion to improve the organization and the performance of the employees as well.

- Since most of the employees in production and manufacturing level are uneducated open door sessions can be carried out so that they will feel easy to express their problems.

- Time barrier must be fixed to solve problem at different levels which will encourage the employees to express their grievance.

- The problems should be solved considering their importance, urgency and implications.

- Counseling of employees need to be carried out periodically which will help the organization to the problem of employees and to solve them which will increase the job satisfaction as well as increase in the efficiency of the employees.

- Informal counseling helps to address and manage grievances in the workplace.

- The management can interact well with the employees whenever there is a problem or grievance. This will make the employee to explain the problem properly. This should be done with no perceptions and no favor.

- Job descriptions, responsibilities should be as clear as possible. Everyone should be informed of company's goals and expectation including what is expected from each individual.

\section{Conclusions}

The company is a better example for those companies who do not have a systematic procedure for dealing with grievances but effectively handle them for the prosperity of the organization. Also the employees find it as a better way to communicate their problems and getting the problems solved in a faster way rather than a set of procedures and stages to solve the issues.

Since they do not find it difficult to take their problems to the management and solve them on time, they are happy with the working environment. They feel satisfied with the informal procedures being followed. Hence they could easily work with job satisfaction as well as a better feel of belongingness.

To a great extent the aggravation of industrial problems depends on manager's approaches and attitude in effective handling of employee grievances. Care should be taken in the way managers approaches the problem and perceiving the pros and cons of the situation.

\section{References}

Antonioni, D. (1998). Relationship Between The Big Five Personality Factors And Conflict Management Styles. International Journal of Conflict Management, 9 (4), 336-355.

Bamber, D., \& Castka, P. (2006). Personality, Organizational Orientations and Self-Reported Learning Outcomes. Journal of Workplace Learning, 18 (2), 73-92.

Bean, R. (1994). Comparative Industrial Relations: An Introduction To Cross-National Perspectives. $2^{\text {nd }}$ Edition. London: Routledge.

Bemmels, B., \& Janice, F.R. (1996). Grievance Procedure Research: A Review and Theoretical Recommendations. Journal of Management, 22(3), 359-385.

Bemmels, B., \& Resyef, Y. (1991). The Roles of Supervisors, Employees and Stewards in Grievance Initiation. Industrial \& Labor Relations Review, 45 (1), 15-31.

Barrick, M.R., \& Mount, M.K. (1991). The Big Five Personality Dimensions and Job Performance: A Meta-Analysis. Personnel Psychology, Spring 1991, 1-26.

Clark, F.C. (1988), The role of the steward in shaping union member attitudes toward the grievance procedure. Labor Studies Journal, Fall 1998

D'Cruz, M.N. (1999). A Practical Guide to Grievance Procedure, Misconduct and Domestic Inquiry. Kuala Lumpur: Leeds Publication.

Desivilya, H.S., \& Yagil, D. (2005). The Role of Emotions in Conflict Management: The Case of Work Team. The International Journal of Conflict Management, 16(1), 55-69.

Holt, J.L., \& Devore, C.J. (2005). Culture, Gender, Organizational Role and Styles of Conflict Resolution: A Meta- Analysis. International Journal of Intercultural Relations, 29(2), 165-196.

Jensen-Champbell, L.A., Gleason, K.A., Adams, R., \& Malcolm, K.T. (2003). Interpersonal Conflict, Agreeableness and Personality 
Development. Journal of Personality, 71(6), 1059-1086.

Labig, C.E., \& Greer, C.R. (1988). Grievance Initiation: A Literature Survey and Suggestion for Future Research. Journal of Labor Research, IX(1), 1-27.

Meyer, D. (1994). The Political Effects of Grievance Handling by Stewards In a Local Union. Journal of Labor Research. 15(1), 33-52.

Rollinson, D.J, Hook, C.M, Foot, M., \& Handley, J. (1996). Supervisor and Management Styles in Handling Discipline and Grievance (part two): Approaches to Handling Discipline and Grievance. Personnel Review, 25(4), 38-55.

William, B.W Jr., \& Davis, K. (1996). Human Resource Management 5th Edition. USA: McGraw Hill. Zikmund, W.G. (2003). Business Research Methods $7^{\text {th }}$ edition. Ohio: Thomson Learning. 